\title{
A new benthic quality index for Italian lakes: how to approach with different lake types?
}

\author{
Bruno Rossaro, Valeria Lencioni, Angela Boggero and Laura Marziali
}

\section{Introduction}

Knowledge about Italian lake macroinvertebrates is still fragmentary. Recently a database referred to 37 Italian lakes (591 species: 373 chironomids, 85 oligochaetes, 67 other aquatic insects, 37 mollusks, and 8 crustaceans) was created. Means of percent of oxygen saturation, transparency, and total phosphorus weighted by taxa abundances were calculated to have a benthic quality index weight (BQIW) for each genus and were used to develop a benthic quality index (BQIL) for each site (Rossaro et al. 2006, 2007). This model was not validated because morphometry (volume, depth), conductivity, alkalinity, and $\mathrm{pH}$ affected community composition more than oxygen and nutrient concentration. We classified lakes into types according to WFD 2000/60/ $\mathrm{CE}$ on the basis of lake altitude, maximum depth, and total surface. Each type was analyzed separately and species assemblages were detected.

Key words: assessment, biomonitoring, lake types, macroinvertebrates

\section{Study sites and methods}

The existing data about benthic macroinvertebrates of the Italian lakes were gathered from previous works published from the 1960s to present and were stored in a large Microsoft Access ${ }^{\circledR}$ database (Rossaro et al. 2007). In the 37 investigated lakes (1217 sampling points) macroinvertebrates were collected in the littoral, sublittoral, and profundal zones using Ekman grabs in samples from the 1960s to 2004, and a Ponar grab from 2004 to 2006. Physical and chemical variables were measured in lakes: water temperature, conductivity, dissolved oxygen, $\mathrm{pH}$, nutrients, anions, and cations.

Lakes were separated into types according to the European Water Framework Directive 2000/60/CE (system B) and 4 groups were created $(\mathrm{AL}=$ Alpine lakes; $\mathrm{ME}=$ Mediterranean lakes): (1) type AL-3, large subalpine lakes, at altitude $<800 \mathrm{~m}$ a.s.l., with maximum depth $\geq 120 \mathrm{~m}$, and surface $\geq 100 \mathrm{Km}^{2}$; (2) type AL-5, shallow subalpine lakes, at alti- tude $<800 \mathrm{~m}$ a.s.l., with maximum depth $<15 \mathrm{~m}$ and with stable thermal stratification; (3) type AL-6, deep subalpine lakes, at altitude $<800 \mathrm{~m}$ a.s.l. and with maximum depth $\geq 15 \mathrm{~m}$; (4) type ME-7, shallow volcanic lakes of Central Italy, with maximum depth $<15 \mathrm{~m}$, and volcanic or pseudovolcanic origin.

Macroinvertebrates were sorted and identified to genus, species group, or species level. Chironomids and oligochaetes were slide-mounted prior to determination. Because environmental data matching biotic samples in our data base were often lacking, a Kohonen Self-Organizing Mapping (SOM, Artificial Neural Networks) was carried out using Matlab R2006b ${ }^{\circledR}$. This program is an unsupervised competitive learning methodology that allows site mapping the sites in a n-dimensional space on the basis of their biological closeness and grouping them into separate clusters (LEK \& GUÉGAN 2000). Environmental variable values can be included in the map in a second step of analysis, but they do not influence ordination. The SOM method was preferred to traditional ordination (e.g., CA) and cluster (e.g., TWINSPAN) analyses because it is less sensitive to outliers and can better detect nonlinear relations. Only taxa present in at least 6 samples were considered for statistical analysis.

\section{Results}

Four lakes (464 sampling sites) were included in type AL-3; 65 taxa were present. Lakes were separated according to macroinvertebrate fauna (Fig. 1): chironomids prevailed in the less eutrophic sites (e.g., Chironomus anthracinus, Microtendipes pedellus, cluster 9), oligochaetes in the most eutrophic ones (e.g., Tubifex tubifex, Potamotrix hammoniensis, clusters 8 and 10). Lakes Garda and Maggiore were separated into clusters according to sampling depth: deep taxa such as Spirosperma sp. and Niphargus sp. characterized sites at $-100 /-300 \mathrm{~m}$ (clusters 2, 4, and 7); the littoral zones were the richest in taxa (clusters 1, 3, and 9). L. Como (characterized by Procladius choreus, Limnodrilus hoffmeisteri, 


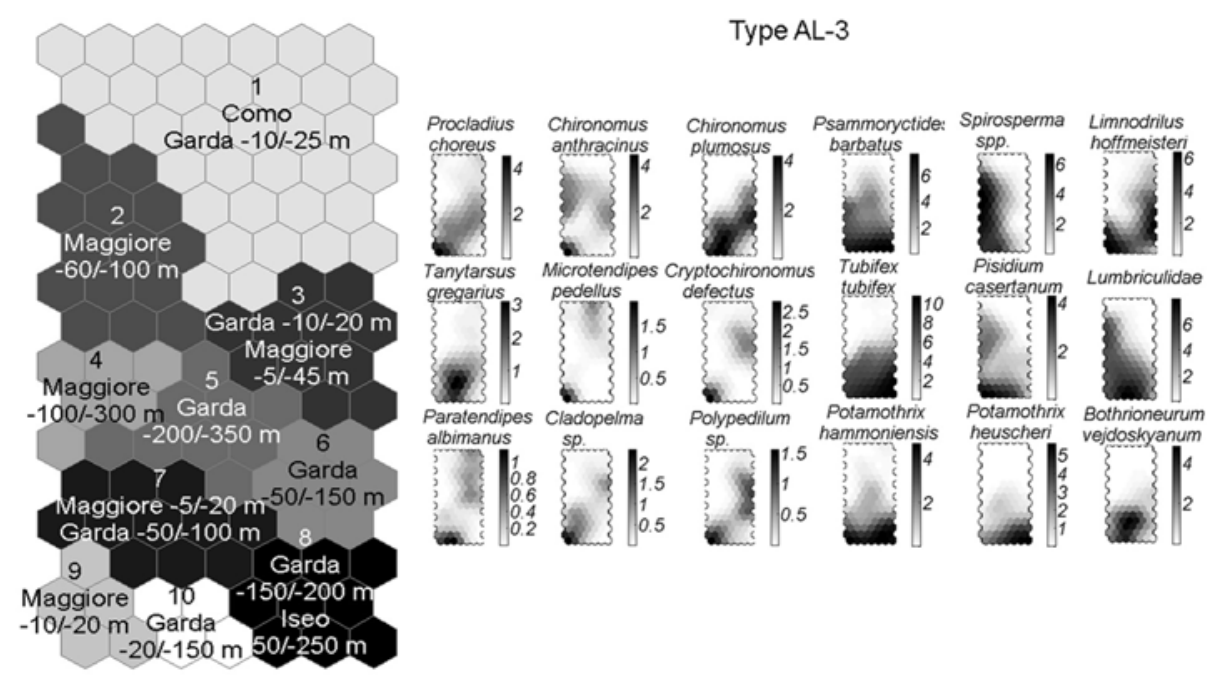

Type AL-5
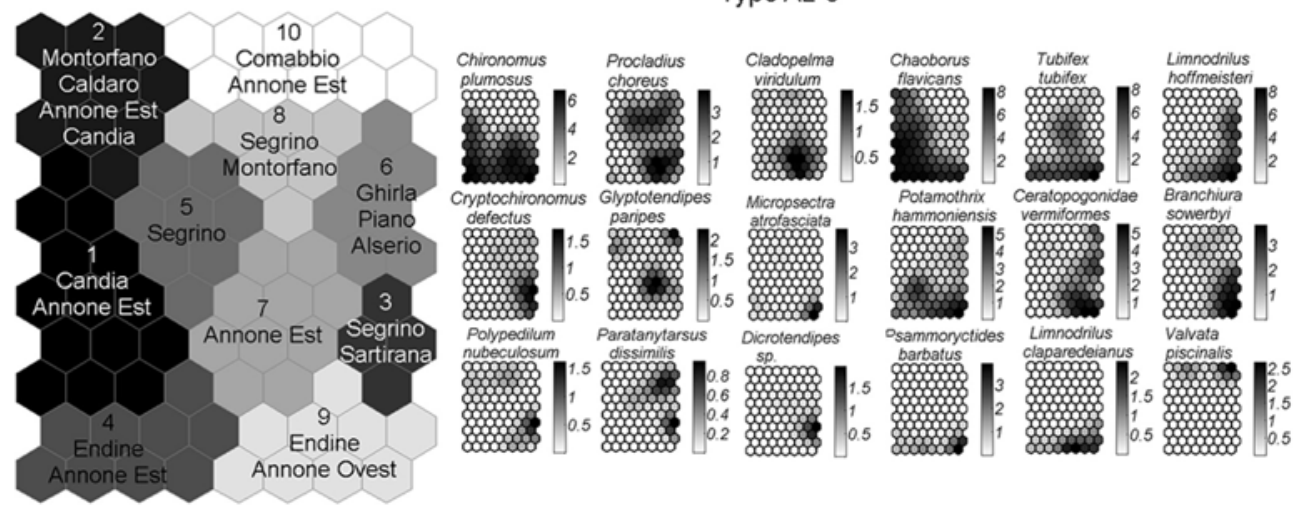

Fig. 1. SOM map for lake type AL-3 (top) and AL-5 (bottom): in left graph sites are plotted in the map and are grouped in clusters according to macroinvertebrate fauna; in small maps (right) the main taxa abundance is plotted (scale represents codebook values). and M. pedellus, cluster 1) and Iseo (colonized mainly by T. tubifex, P. hammoniensis, and Potamotrix heuscheri, cluster 8) showed a rather uniform taxa association in the different sites.

Type AL-5 comprised 12 lakes (303 sites), where 50 taxa were recorded (Fig. 1). Lakes Annone Est, Montorfano, Endine, and Segrino were divided into sub-basins. Eutrophic species (e.g., Chironomus plumosus, Chaoborus flavicans, T. tubifex, clusters 4 and 8) prevailed in Endine, Annone Est, and Annone Ovest; less tolerant taxa (e.g., Paratanytarsus dissimilis, Valvata piscinalis, clusters 6, 8, and 10) were present in Comabbio, Ghirla, Piano, and Montorfano.

Most lakes (18 lakes, 545 sampling sites) were included into type AL-6, which was also the speciesrichest type, with a total of 104 taxa (Fig. 2). L. Mergozzo was separated from the other lakes, being more oligotrophic: many taxa dominated here. It was also divided according to depth (clusters 1 and 2). Few taxa indicators of eutrophic state were present in the other lakes (cluster 3), where C. flavicans and C. plumosus were especially abundant. A large cluster (3) character- ized by few tolerant species included most stations from different lakes.

Type ME-7 included 3 lakes (202 sampling points) and 54 taxa (Fig. 2). Lakes were well separated into different clusters, and each lake was separated into basins with different ecological conditions. Most taxa were present in the oligotrophic Lake Bolsena, which was separated into clusters 1, 7, and 9; Psectrocladius oxyura, Cryptochironomus defectus, Pisidum casertanum, V. piscinalis and Echinogammarus sp. were the most abundant. Indicator species of eutrophic condition (e.g., T. tubifex, Bithynia tentaculata, C. plumosus) dominated in Bracciano (clusters 3 and 4). Lake Vico was particularly poor in species.

\section{Discussion}

Different lake types based on morphometric characteristics were shown to separate according to macroinvertebrate fauna. In profundal lakes (types AL-3 and AL-6) depth was the most important variable determining spe- 
Fig. 2. SOM map for lake type AL-6 (top) and ME-7 (bottom): see Fig. 1 for explanation.
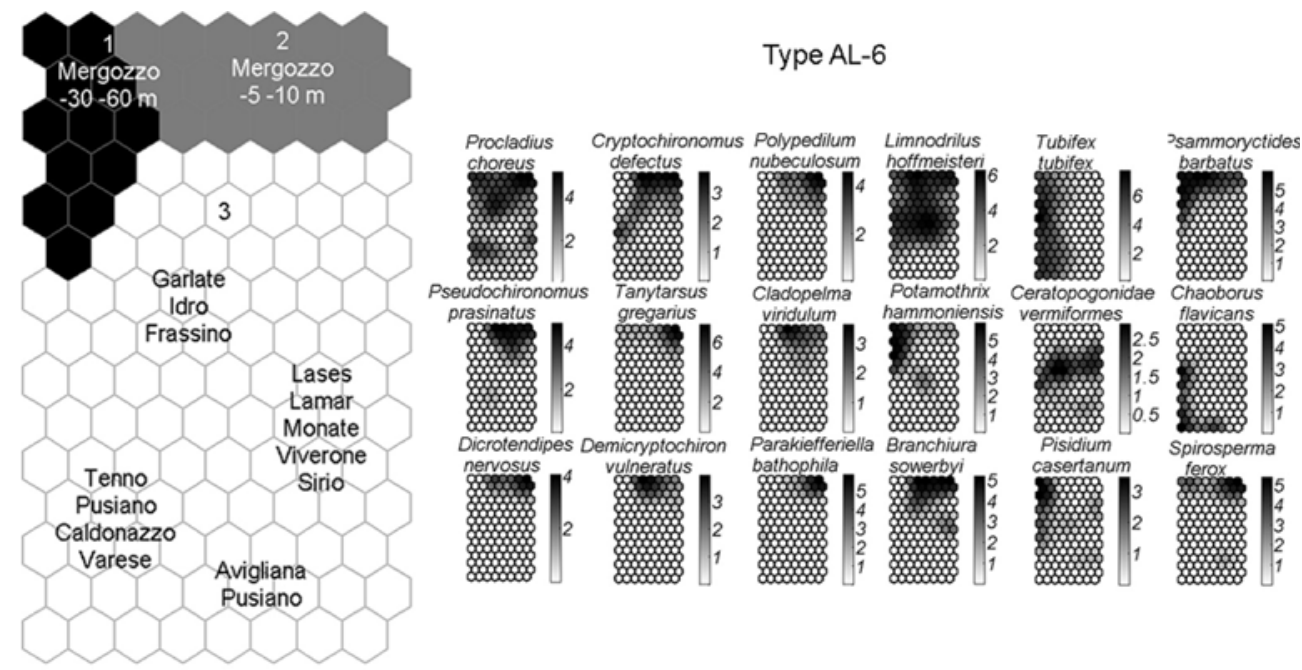

Type ME-7
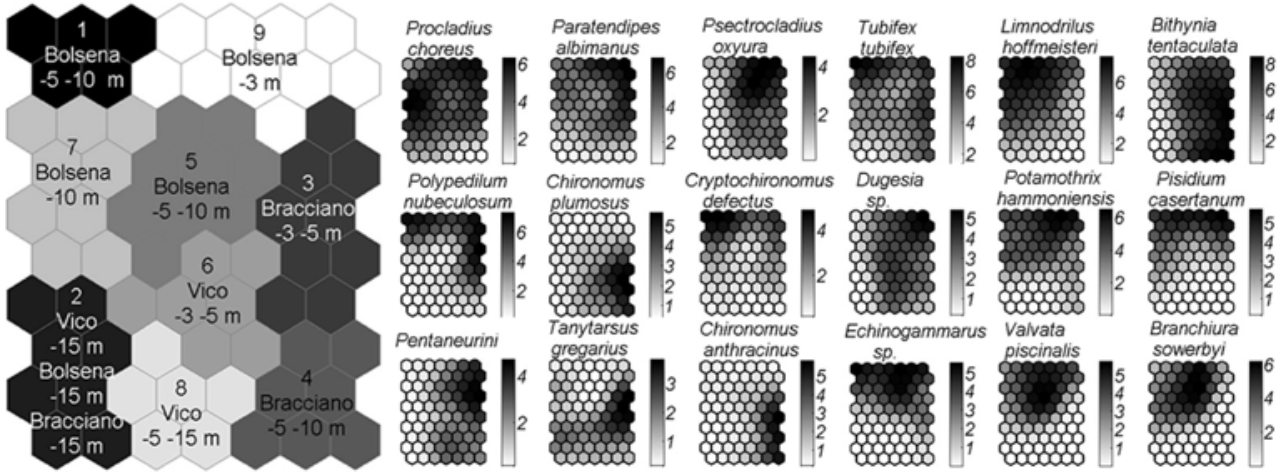

cies composition; in other lakes, clusters were separated according to their trophic state (TP), conductivity and dissolved oxygen. The importance of depth in explaining species distribution was stressed by many authors (VERNEAUX et al. 2004).

Nonlinear neural network SOM analysis ordered sites and species, which are less influenced by outliers with respect to linear ordination methods used in the past to order benthic macroinvertebrates in lakes (KANSANEN et al. 1990).

The development and validation of a model for each Italian lake type is not yet possible because (1) pristine conditions are often lacking, and reference sites have not been established; (2) all trophic levels, from oligotrophy to eutrophy, are not always available. Statistical models could probably help to overcome this drawback.

\section{Acknowledgements}

This work was supported by: (I) European Commission Directorate General JRC Joint Research Centre Institute for
Environment and Sustainability Inland and Marine Waters Unit contract No Imw- Eewai-20041119-1 "Support for a Research Project on the Assessment of the Ecological State of Lakes by Macroinvertebrates In Lombardy"; H05-IMW/ 2004/D/31594 Scientific Support For Taxonomic Analysis Of Benthic Invertebrates; Negotiated procedure H. 05/06 "Database on benthic invertebrates in sub alpine lakes in Italy" (II) Italian Murst First 2003-2005: "Taxonomy, Ecology, Biogeography of Diptera Chironomidae".

\section{References}

Kansanen, P.H., L. Passivirta \& T. Väyrynen. 1990. Ordination analysis and bioindices based on zoobenthos communities used to assess pollution of a lake in Southern Finland. Hydrobiologia 220: 153-170.

LeK, S. \& J.F. GuÉgan. 2000. Artificial Neuronal Networks. Application to ecology and evolution. Springer Verlag, Berlin.

Rossaro, B., A. Boggero, V. Lencioni, L. Marziali \& A. SoliMINI. 2006. Tools for the development of a benthic quality index for Italian lakes. J. Limnol. 65: 41-51. 
Rossaro, B., L. Marziali, A.C. Cardoso, A. Solimini, G. Free \& R. Giacchini. 2007. A biotic index using benthic macroinvertebrates for Italian lakes. Ecol. Indic. 7: 412-429.
Verneaux, V., J. Verneaux, A. Schmitt, C. Lovy \& J.C. LamBERT. 2004. The Lake Biotic Index (LBI): an applied method for assessing the biological quality of lakes using macrobenthos; the Lake Châlain (French Jura) as an example. Ann. Limnol. 40: 1-9.

Authors' addresses: B. Rossaro, Department of Biology, Section of Ecology, University of Milan, Via Celoria 2620133 Milan, Italy. E-mail: bruno.rossaro@unimi.it.

V. Lencioni, L. Marziali, Section of Invertebrate Zoology and Hydrobiology, Museo Tridentino di Scienze Naturali, Via Calepina 14, 38100 Trento, Italy.

A. Boggero, Consiglio Nazionale delle Ricerche - Istituto per lo Studio degli Ecosistemi, Largo Tonolli 50/52, 28922 Verbania Pallanza (VB), Italy. 